\title{
Margaret McCartney: Time to give patients informed choice
}

\author{
Margaret McCartney general practitioner, Glasgow
}

Time is short: 10 minutes. Come in, take a seat, make introductions. Remove a jacket. Say what's wrong. Talk freely. I ask questions to exclude or include a diagnosis. We may need a translator, who may or may not have been organised. On average, we discuss two or three problems.

Then an examination, which may require undressing, a chaperone, screens pulled around. We discuss findings, uncertainties, a proposed course of (in)action, and decisions (perhaps to defer a decision). My computer prompts me to review drugs, ask about smoking, and switch drugs to cheaper varieties. A few words may reveal why the patient is here at all. We may discuss follow-up and whether I can leave voicemail messages. Then re-dressing, leaving, typing up the notes, and writing reminders for later (for referrals, finding information, and so on).

Into this mix goes the judgment from the Supreme Court essentially that patients, not doctors, should decide what risks to take and that doctors should ensure that patients have balanced information on treatments. ${ }^{1}$ At this I cheer. For almost 15 years a theme of my writing has been the need for unbiased information so that citizens can make informed choices about interventions, particularly screening.

Emphasis on the need for choice - rather than submission-has been a long time coming. However, screening invitations are generally sent by post, with printed or web based information. We still lack standardised, face to face discussions to ensure understanding and answer any questions. This exemplifies the problem: even the most planned healthcare does informed choice badly.

Giving patients better information requires a systematic overhaul. It is simply not possible in a 10 or 12 minute consultation to outline every hazard and every potential option for treatment. Remember: not everyone is literate, able to access the internet, or in a position to seek information on his or her own health. Patient information leaflets can be patchy, and information sheets inside drug packets are largely there to protect the manufacturer, not to help patients make informed choices. Citizens and professionals can struggle to make sense of risk: we need help to do it well.

We should provide universal access to coherent information for people with all levels of literacy on the problems we deal with daily, to outline choices, uncertainties, hazards, and the benefits of interventions. This needs to be tested for effectiveness (and harms). And we must find more time to help patients make choices. This does not just mean help from pharmacists and nurses: we need to get rid of every politically driven, wasteful thing doctors do that takes away time from patients.

Competing interests: I have read and understood the BMJ policy on declaration of interests and declare the following interests: I'm an NHS GP partner, with income partly dependent on Quality and Outcomes Framework points. I'm a part time undergraduate tutor at the University of Glasgow. I've written two books and earn from broadcast and written freelance journalism. I'm an unpaid patron of Healthwatch. I make a monthly donation to Keep Our NHS Public. I'm a member of Medact. I'm occasionally paid for time, travel, and accommodation to give talks or have locum fees paid to allow me to give talks but never for any drug or public relations company. I was elected to the national council of the Royal College of General Practitioners in 2013 and am chair of its standing group on overdiagnosis. I have invested a small amount of money in a social enterprise, Who Made Your Pants?

Provenance and peer review: Commissioned; not externally peer reviewed.

Follow Margaret on Twitter, @mgtmccartney

1 Dyer $\mathrm{C}$. Doctors should not cherry pick what information to give patients, court rules. $B M J$ 2015;350:h1414.

Cite this as: BMJ 2015;350:h3311

๑ BMJ Publishing Group Ltd 2015 